\title{
Development and Publication of Volcanic Base Map Data
}

\author{
Gen NAGANO $^{\mathrm{a},}{ }^{*}$, Hironobu TSUCHIHASHI $^{\mathrm{a}}$, Katsuhiro OKAMOTO ${ }^{\mathrm{a}}$, Yoshinori NUMATA ${ }^{\mathrm{a}}$ \\ ${ }^{a}$ Geospatial Information Authority of Japan, nagano-g96pa@mlit.go.jp \\ * Corresponding author
}

Keywords: Volcanic Base Map Data, topographic map, volcano, vector data, raster image, web map

\begin{abstract}
:
Japan has 111 active volcanoes accounting for about 7 percent of active volcanoes in the world and many volcanic disasters have been recorded so far. Geospatial Information Authority of Japan (GSI) proceeds to develop Volcanic Base Map, which depicts specific landforms of volcanoes precisely from 1979 to 2009 for the purpose of providing basic information for formulating various types of volcanic disaster prevention plans and volcano research. Although Volcanic Base Maps have been created by aerial photogrammetry for 31 active volcanoes throughout Japan as a paper map with a scale of 1:2,500 to 1:10,000, they have not been able to meet the needs of recent volcanic disaster prevention measures and have not been fully utilized in disaster emergency measures due to the following reasons: (1) There are undeveloped volcanoes because creation pace was limited for one volcano per year in the conventional creation method; (2) Considerable number of years has passed after its maintenance, so the latest terrain and infrastructure have not been updated; (3) It is impossible to cover the whole area of the volcano and the range of damage estimation because the development around the crater is mainly focused; (4) Basic information such as disaster prevention related facility information, which is necessary for the formulating volcanic disaster prevention plan and disaster emergency measures, has not been covered; (5) Since they were provided by a paper map for a fee, they were not suitable for advanced application using GIS.
\end{abstract}

In order to solve the above issues and to promptly develop and provide maps of volcanoes, we have revised methods of making and acquisition criteria and have newly created Volcanic Base Map Data from 2017. Contour line data was created using digital stereoscopic machine in the conventional method of Volcanic Base Map, but it was changed to generate automatically by Digital Elevation Model of airborne laser survey. Also, we have changed to create features such as roads, buildings and disaster prevention-related facilities by using existing geospatial data maintained by GSI and materials collected from relevant organs. Therefore, the process of numerical mapping and associated photocontrol points surveying, pricking and aerial triangulation becomes omissible, and the number of creating maps can be increased. Although some of the designated evacuation shelters and heliports are not acquired in the conventional Volcanic Base Map, they are added as an acquisition item in Volcanic Base Map Data in order to make it easier to utilize to disaster prevention plan and emergency measures.

Volcanic Base Map Data consists of three types of raster image data (base map, colour relief map and photomap, Figure 1), two types of vector data (Shapefile and Digital Mapping data) and GSI Tile data, is started to provide and publish on March 31, 2017 on the website of GSI and 14 volcanoes are provided as of October 2018. While Volcanic Base Map Data is possible to update in a very short time compared to conventional paper maps by maintaining and creating as numerical data, if there is a change in the contents of display such as disaster prevention related facilities and important infrastructures, it is necessary to consider a mechanism that can quickly update and publish maps. Furthermore, it is necessary to promote the products in each of the Volcano Disaster Management Councils and to continuously grasp the needs of users to be utilized more in the future.
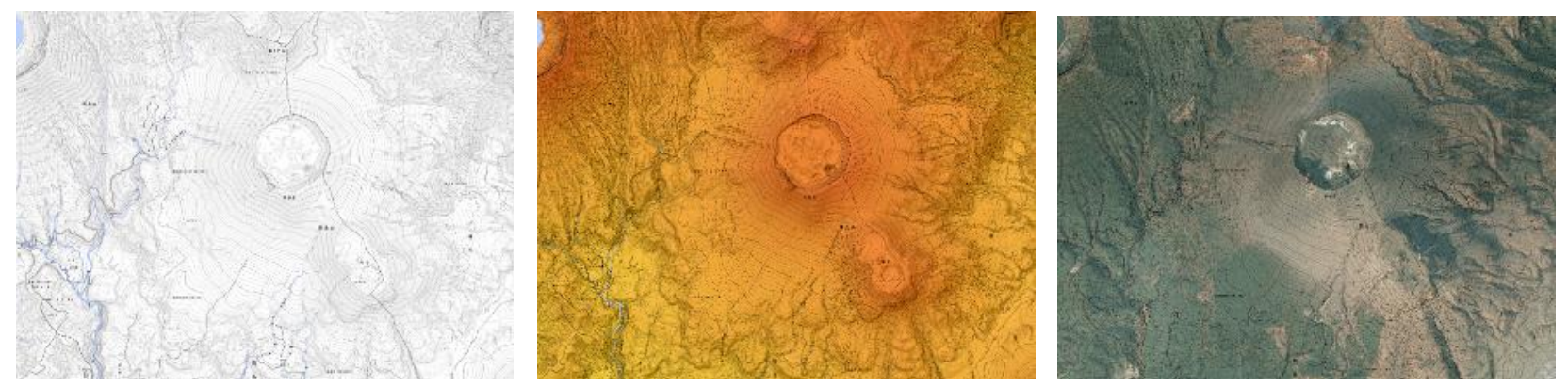

Figure 1. Examples of raster image data of Volcanic Base Map Data. (left: base map, center: color relief map, right: photo map) 